\title{
Capital social e desempenho institucional no SUAS das cidades de Caxias do Sul e Novo Hamburgo
}

\section{Social capital and institutional performance in SUAS in Caxias do Sul and Novo Hamburgo}

\author{
Douglas Marques \\ Everton Rodrigo Santos \\ Scarleth Gabriela Ribeiro Duarte
}

\section{Resumo}

O presente artigo baseia-se na teoria de Putnam, buscando verificar o impacto do capital social no desempenho institucional do Sistema Único de Assistência Social (SUAS) no Rio Grande do Sul, em especial nas cidades de Caxias do Sul e de Novo Hamburgo. Desta forma, pretendemos demonstrar, comparativamente, a relação entre o acúmulo do capital social e a qualidade do desempenho institucional nas políticas públicas. Utilizamo-nos de pesquisa de opiniáo pública, tipo survey, por meio de duas baterias de testes nas cidades em tela, totalizando 382 questionários aplicados diretamente aos usuários do SUAS. Neste sentido, estatisticamente foi possível afirmar nossa hipótese, qual seja, que existe relação positiva entre capital social e a qualidade do desempenho institucional nas políticas públicas, assim, na medida em que cresce o estoque de capital social, melhor a população avalia as políticas públicas.

\section{Palavras-chave}

Capital Social; Políticas Públicas; Desempenho Institucional; Rio Grande do Sul.

\begin{abstract}
The present study is based on Putnam's theory of social capital and its impact on the institutional performance of the National Social Assistance System (SUAS), in Rio Grande do Sul state, especially in the cities of Caxias do Sul and Novo Hamburgo. Thus, we intend to demonstrate comparatively the relationship between the accumulation of social capital and the institutional performance in the public policy. Regarding the methodological delimitation, we used a survey research, and 382 questionnaires were directly applied to SUAS users. In this sense, it was possible to affirm our hypothesis that there is a positive relationship between social capital and the institutional performance of public policies, thus, it's possible to affirm that in so far as the stock of social capital grows, also occurs the growth of institutional performance in the public policy.
\end{abstract}

\section{Keywords}

Social Capital; Institutional Performance; Public Policy; Rio Grande do Sul. 


\section{Introdução}

A democracia e sua estabilidade neste início do século XXI na América Latina, e particularmente no Brasil, ainda são questôes centrais na agenda política e social da região e do país. Conforme Nobre (2016), países com pouca participação popular em seus sistemas políticos costumam guardar alguma relação com seus índices altos de desigualdade econômica ${ }^{1}$. Diante deste cenário, discute-se, por um lado, se o ideal de uma sociedade democrática seria formado por um conjunto de leis e instituiçóes fortes; e, por outro, se a sociedade democrática seria formada por laços e redes sociais e pelo respeito às virtudes cívicas (NORTH, 2007; PUTNAM, 2000; BAQUERO, 2013).

Quando analisamos as políticas públicas na atualidade - sendo elas o meio pelo qual os governos traduzem seus propósitos em programas e açôes, os quais produzirão resultados ou as mudanças desejadas no mundo real (SOUZA, 2006) -, constata-se um grande desafio por parte dos governos, que precisam responder às demandas sociais, articulando escassos recursos. Muito embora nas últimas décadas a sociedade brasileira tenha experimentado um crescimento significativo $\mathrm{da}$ descentralização de políticas públicas, persistem ainda os dilemas para que essas políticas estejam de fato voltadas para o aprofundamento da democracia e para o seu desempenho institucional.

Num primeiro momento, olhando-se da perspectiva institucional, esse esforço dependeria exclusivamente das leis, das instituições e dos gestores públicos. Todavia, pela perspectiva da teoria do capital social de Putnam (2000), seríamos levados a observar que os aspectos socioculturais de uma determinada região têm influência direta na qualidade do desempenho institucional das políticas públicas. Particularmente nos interessa, por razões geográficas e socioculturais, estudar as cidades de Novo Hamburgo e Caxias do Sul, no estado do Rio Grande do Sul (RS), que sofreram, predominantemente, a influência da imigração alemã e italiana, respectivamente, a partir do século XIX.

Nesta direção, de forma original, este trabalho busca, à luz da teoria do capital social, analisar comparativamente o desempenho institucional do Sistema Único de Assistência Social (SUAS) nas cidades de Caxias do Sul e Novo Hamburgo, no Rio Grande do Sul. Nessa perspectiva, a nossa hipótese de trabalho sugere, a partir da

\footnotetext{
${ }^{1}$ O leitor pode aprofundar o tema consultando o Relatório da Economist Inteligence Unit (2016). Considera-se a existência de 24 democracias ditas "completas" no mundo, atingindo notas superior a 8. O Brasil teve nota 7,38. (BRAZIL, 2019).
} 
relação definida por Putnam (2000), que o acúmulo de capital social existente numa determinada região, ou seja, suas relaçóes de confiança interpessoal, de participação política e a cultura cívica estâo positivamente correlacionadas com a qualidade do desempenho institucional das políticas públicas. A metodologia utiliza resultados de pesquisa quantitativa tipo Survey, tendo sido realizadas duas baterias de testes em 2016, uma na cidade de Caxias do Sul, constituída de 211 questionários, outra na cidade de Novo Hamburgo, constituída de 171 questionários, totalizando 382, com erro amostral de 5\% e coeficiente de confiança de 95\%. Os questionários foram aplicados diretamente aos usuários do SUAS, juntos aos aparelhos públicos dos Centros de Referência de Assistência Social (CRAS) e Centros de Referência Especializado de Assistência Social (CREAS), locais estes onde a população acessa esta política pública.

Assim, num primeiro momento, buscaremos apresentar nossa compreensão sobre as políticas públicas no contexto brasileiro, sugerindo a relevância da cultura política como elemento de sustentação da democracia; em seguida, lançaremos o debate sobre capital social como um vetor de desenvolvimento, em especial para o desempenho das políticas públicas. Por fim, demonstraremos, a partir de uma perspectiva culturalista, a associação positiva entre capital social e desempenho institucional.

\section{Politicas públicas: institucionalismo ou culturalismo?}

Ao analisarmos o contexto brasileiro, os estudos sobre as políticas públicas tiveram início no século XX, havendo nos anos 1980 uma retomada das análises sobre políticas de gestão dos governos, de políticas públicas e de políticas em geral. Segundo Miceli (1999), a tradição de análise das políticas públicas segue a escola anglo-saxônica, mais especificamente a norte-americana, pelos pressupostos do "antiestatismo liberal" e pelos estudos da cultura política, ensejando os estudos sobre "o Estado em ação". Desta forma, os estudos têm se dividido em três campos predominantes: 1) regime político, instituiçôes políticas ou Estado, 2) políticas setoriais e seus problemas internos, e 3) avaliação de políticas públicas (MICELI, 1999).

Sobre os tipos de políticas públicas, a literatura especializada tem cotejado diferentes abordagens, como a atenção às dimensões técnica e política de Bozeman e Pandey (2004); a distinção entre as políticas reais, simbólicas e pseudopolíticas de Gustafsson (1983); as políticas do tipo clientelista, de grupo de interesses, empreendedoras e majoritárias de Wilson (1983); as abordagens de políticas 
regulatórias, distributivas, constitutivas e redistributivas de Lowi (1964); a operacionalização de políticas públicas pelos modelos: principal-agente, rede de políticas públicas, elitista e pluralista de Secchi (2014), são alguns exemplos.

Nesta direção, na perspectiva de Secchi (2014, p. 2), “[...] política pública é uma diretriz elaborada para enfrentar um problema público, constituindo-se de uma intencionalidade pública e a resposta a um problema público". Complementa Lahera (2012) que políticas públicas indicam a ação de uma autoridade pública ao colocar em marcha uma política ou programa. Para Pase e Santos (2011), as políticas públicas são o conjunto de ações do Estado postas em marcha mediante programas e projetos para efetivar concepçóes acerca da saúde, da educação, da assistência social, da segurança, da economia, da infraestrutura, entre outras. Para os limites deste trabalho, respaldados por Souza (2006, p. 26), entendemos política pública como

O campo do conhecimento que busca, ao mesmo tempo, "colocar o governo em ação" e/ou analisar essa ação e, quando necessário, propor mudanças no rumo ou curso dessas açóes. Em outras palavras, o processo de formulação de política pública é aquele através do qual os governos traduzem seus propósitos em programas e açôes, que produzirão resultados ou as mudanças desejadas no mundo real.

Observa-se uma tensão embrionária na formulação das políticas públicas, expressando-se na bifurcação: a formulação das políticas públicas tem se dado outorgada pelo Estado de "cima para baixo", enquanto a sua implantação dependerá, a grosso modo, da iniciativa de grupos sociais, influenciando de "baixo para cima". Desta forma, num primeiro momento, coloca-se em evidência uma abordagem estatista, considerando que políticas públicas são exclusivamente emanadas pelo Estado. Num segundo momento, uma abordagem multicênica na qual outros grupos sociais e políticos também contribuem para a formulação de políticas. Neste contexto, entre as políticas públicas no Brasil, nossa abordagem volta-se para a Política Nacional de Assistência Social (PNAS), que vem sendo operacionalizada por meio do SUAS (BRASIL, 2015, p. 33), no qual "ações são organizadas em sistema descentralizado e participativo, constituído pelas entidades e organizaçóes de assistência social, articulando meios, esforços e recursos, e por um conjunto de instâncias deliberativas", composto por dois níveis de proteçáo social: básica e especial. 
Considerando a inclinação da experiência brasileira para estudos de políticas públicas voltados para a ação do Estado, numa perspectiva institucionalista, coloca-se a problemática: as políticas públicas dependeriam exclusivamente das instituições políticas para promover um bom desempenho institucional? $\mathrm{Ou}$ as políticas públicas teriam que contar com elementos da cultura política e com recursos sociais como vetores para se atingir um bom desempenho? Considerando a atual crise das instituiçóes políticas e o cenário de tensôes entre Estado e a sociedade, a bibliografia, grosso modo, tem se bifurcado entre duas grandes tradiçóes de estudos, o institucionalismo e o culturalismo (NORTH, 2007; PUTNAM, 2000) para explicar o desempenho institucional dos governos.

Neste sentido, mesmo considerando a realização de eleições limpas, a eficiência governamental e o consenso entre algumas das principais tarefas da democracia, a sua estabilidade necessita de uma infraestrutura social adequada (FERRAZ, 1971 e 2016). O aspecto da infraestrutura social envolve a atenção de Baquero (2016) na medida em que ele utiliza o conceito de "democracia inercial" para sugerir que, no Brasil, por meio das teorias de escolhas racional e institucional, afirmava-se que as instituições formais, aos poucos, seriam capazes de solucionar (automaticamente) os problemas sociais e políticos. Contudo, essa perspectiva não tem se comprovado, pois, quando as crises econômicas se instauram, elas produzem perda de credibilidade nas instituiçóes, colocando em xeque a própria legitimidade de um governo democraticamente eleito (BAQUERO, 2016). O fato fica evidente, na atualidade, conforme a última pesquisa de opinião pública sobre a avaliação do Governo Federal, em que $73 \%$ da população considera a gestão péssima ou ruim ${ }^{2}$ (DATA FOLHA, 2018).

Nesta direção, ampliam-se os estudos voltados para a qualidade e recursos sociais de uma sociedade capaz de colaborar com a complexa tarefa do Estado de sustentação da democracia e da implantação e das políticas públicas (BAQUERO e PRÁ, 2007; SANTOS e NUNES, 2016; PUTNAM, 2000). Quando analisamos essas políticas na atualidade, em especial no contexto do Rio Grande do Sul, constatase, entre outros, o grande desafio do aprofundamento da democracia, que não é recente, para ação dos governos, os quais necessitam responder às demandas sociais e

\footnotetext{
2 Pesquisa Survey realizada com 2772 pessoas no mês de setembro de 2018, com erro amostral de 2\% e coeficiente de confiança de 95\%. Avaliação do Governo Federal: Bom/ótimo (5\%); Regular (20\%); Ruim (73\%); Não sabem (2\%). Disponível em.: <https://g1.globo.com/politica/eleicoes/2018/eleicaoem-numeros/noticia/2018/09/29/pesquisa-datafolha-de-29-de-setembro-para-presidente-por-sexoidade-escolaridade-renda-regiao-e-cor.ghtml>. Acesso em: 22 out. 2019.
} 
articular os recursos escassos do Estado. Diante deste panorama tem-se voltado para os estudos do capital social e da cultura política como elementos imprescindíveis para a sustentação das instituições democráticas (PUTNAM, 2000; ARROW, 1974; DOWBOR, 2003; GIDDENS, 2007; TABELLINI, 2005; BAQUERO e PRÁ, 2007; SANTOS, 2013, entre outros).

Colocam-se em cheque duas perspectivas: as instituições como variáveis independente e dependente. Na primeira vertente teórica, a cultura política exercida pelos cidadãos e governos, bem como a qualidade do tecido social, não se constitui como elemento central para se alcançar o bom desempenho institucional, atribuindo um peso determinante às instituiçóes, às leis e aos recursos públicos (TABELINI, 2005; OLSON, 1999). $\mathrm{Na}$ segunda vertente, as instituiçôes como variável dependente, segundo Wittmann e Ramos (2004), atenta-se para os pré-requisitos sócio-históricos e culturais necessários para o desenvolvimento social, entre eles: a integração social, os indicadores empíricos, sociais e econômicos e a geração e distribuição de capital social, estes como elementos centrais para o bom desempenho institucional.

Nessa direção, sugere-se que a cultura política, os valores cívicos e a confiança são aspectos que auxiliam as instituições democráticas e os governos em geral no seu papel de promover o desenvolvimento econômico (TABELINI, 2005), sendo "[...] esta uma questão que nenhuma 'engenharia institucional' pode resolver" (BAQUERO, 2003, p. 17). Neste caso, as políticas públicas, para constituírem-se fortes e participativas, deveriam combinar os aspectos formais (institucionais) e informais (socioculturais) da sociedade.

\section{Capital social e desempenho institucional}

Conforme Giddens (2007), considerando o cenário europeu, mediante pesquisa realizada em 11 países, constata-se que a confiança nas instituições do governo caiu em seis deles. Esse cenário pode ser replicado a outros contextos, como o brasileiro, ao constatarmos uma significativa redução no nível de confiança nas instituições ${ }^{3}$. A perda de confiança, a insatisfação e a desvalorização política dos governos por longos períodos comprometem as instituiçôes democráticas.

\footnotetext{
3 Trata-se de um estudo tipo Survey realizado com 2.002 pessoas, em 141 municípios brasileiros, entre os dias 18 e 21 de julho de 2014. In: http://g1.globo.com/jornal-nacional/noticia/2013/08/brasileirosconfiam-menos-nas-instituicoes-diz-pesquisa-do-ibope.html. Acesso em out., 2019.
} 
Entre outros, aspectos como a centralização das decisões do Estado face às iniciativas regionais e locais de participação, a desaceleraçáo do crescimento econômico, a falta de governabilidade política dos Estados, o crescimento da corrupção, o declínio dos grupos participativos e o declínio do capital social podem ter contribuído para um cenário de desconfiança nas últimas duas décadas (GIDDENS, 2007). Contudo, os governos são elementares numa democracia, inclusive para recuperar a perda de confiança, visto que sua funçáo estratégica de governança articula instituiçôes do mercado, do Estado e da sociedade civil.

Um dos primeiros usos do termo "capital social" na literatura acadêmica foi feito por Hanifan (1916), relacionado a uma abordagem em um centro comunitário rural no Estado da Virgínia Ocidental, nos Estados Unidos. Desde então, o capital social, vem se constituindo como um conceito polissêmico, abrangendo os aspectos sociológico, econômico, político, cultural. Diante de várias interpretaçôes do conceito de capital social, a perspectiva histórica e econômica de Wittman e Ramos (2004, p. 42) esclarece que "[...] a base do capital social é a constituição de um sólido sistema de intercâmbio de signos e informaçóes [...] Mais exatamente a transformação do credere (confiança) em crédito". No sentido empregado pelos autores, a contribuição do capital social foi fundamental para o desenvolvimento do Estado do Rio Grande do Sul no período colonial. De outro ponto de vista, partindo de estudos culturalistas, Szreter (1999, p. 406) irá se apoiar nos pressupostos das relações de confiança e na qualidade das relações entre grupos sociais como bases constitutivas de capital social, assim, "[...] capital social decorre de relaçóes mutuamente respeitosas e fidedignas que permitem a um grupo seguir suas metas comuns com maior eficiência do que seria possível em outras circunstâncias" (p. 406). Para Fukuyama (1996), a compreensão da vida econômica, ou para o nosso caso, o desempenho institucional de uma política pública, está intrinsecamente ligado à vida social, pois “[...] o capital social decorre da prevalência de confiança numa sociedade [...] Difere de outras formas de capital humano na medida em que geralmente criado ou transmitido por mecanismos como a religião, tradição ou hábito histórico" (p. 41).

Entre outros importantes autores das ciências sociais que vêm contribuindo para o debate conceitual sobre o capital social, citamos Bourdieu (1980) e Coleman (1988). Para o primeiro autor, se trata de um

[...] conjunto de recursos atuais ou potenciais que são colocados à posse de uma rede durável de relaçóes mais ou menos institucionalizadas pelo convívio e pelo reconhecimento; ou, em outras palavras, ao 
pertencimento de um grupo, como um conjunto de agentes que não são apenas dotados de propriedades comuns, mas são também unidos por laços permanentes e úteis. (BOURDIEU, 1980, p. 80).

E, para o segundo autor,

[...] o capital social é definido por sua função. Ele não é uma entidade individual, mas uma variedade de diferentes entidades com dois elementos comuns: todas elas consistem em algum aspecto das estruturas sociais e elas facilitam certas açóes dos atores - sejam pessoas ou atores corporativos - dentro da estrutura. (COLEMAN, 1988, p. 98).

Contudo, nosso entendimento sobre capital social recai sobre a perspectiva de Putnam (2000), na qual as instituições são importantes marcos político-legais que tencionam mudanças na sociedade, mas essas são moldadas pelo contexto sociocultural onde estão inseridas. Desta forma, a confiança interpessoal de uma sociedade, o seu engajamento cívico e a sua participação política estão na base do sucesso de instituições democráticas estáveis e eficazes. Nesse sentido, Putnam (2000), ao pesquisar a realidade italiana por mais de 20 anos, tem como pressupostos teóricos buscar compreender quais são as condições necessárias para a criação de instituições fortes, eficazes e responsáveis. Assumindo um viés culturalista, o autor vai atrelar características do contexto sociocultural para explicar porque a Itália do Norte teve melhor desempenho institucional e capacidade de governança do que a Itália do Sul. Dessa forma, capital social, para Putnam (2000, p. 137), diz respeito ao

Conjunto de recursos sociais possuído por um grupo, através de redes de trabalho com as quais se constitui uma comunidade cívica, sentimentos de solidariedade e igualdade com os demais membros da comunidade, normas de cooperação, reciprocidade, confiança e atitudes positivas, reveladas através da confiança no outro, no governo e no funcionamento das instituiçóes.

Nesta direção, Putnam (2000) conclui a existência de uma significativa associação entre engajamento cívico, redes de confiança interpessoal e o desempenho institucional das instituiçóes políticas. No mesmo sentido, Inglehart (2001, p. 88), sugere que o debate pode ser ampliado, pois, "[...] ciertas variables culturales, económicas y políticas guardan uma relación estrecha”. Ademais, recentes pesquisas apontam para que a associação entre capital social e desempenho institucional, definida por Putnam (2000), pode ser replicada ao 
contexto do Rio Grande do Sul (BAQUERO, 2013; SANTOS, 2013). Desta forma, seguindo a tradição de Putnam (2000), o desempenho institucional será analisado nas cidades em tela, considerando que um governo ou de uma política pública pode ser sinônimo de eficácia na medida em que: 1) realizam suas açôes com regularidade; 2) São sensíveis às demandas sociais da população; e, 3) realizam os propósitos e objetivos institucionais.

\section{Capital social nas cidades de Caxias do Sul e Novo Hamburgo}

No Brasil, em especial no Rio Grande do Sul, pesquisas vêm replicando o arcabouço teórico de Putnam (2000), buscando explicar significativos contrastes regionais entre o "Norte gaúcho", com pouca escravidão e a presença do minifúndio, e o "Sul gaúcho", com a presença marcante do latifúndio e do trabalho escravo (BANDERA, 2003; SANTOS, 2013; BAQUERO, 2015; PASE, 2016). Dessa forma, os estudos têm sugerido para um acúmulo maior de capital social no Norte, em especial na cidade de Caxias do Sul (BANDERA, 2003; BASTOS, 2008, muito embora se constate também a presença positiva do capital social no município de Novo Hamburgo (SANTOS, 2013; SANTOS e NUNES, 2016), indicando, assim, a constituição de uma comunidade cívica, sugerindo que poderia haver um melhor desempenho das instituições e das políticas públicas. Este acúmulo de capital social, para os limites deste trabalho, não guarda uma relação direta com as questões culturais e/ou étnicas nessas cidades, como resultado daquilo que tem sido chamado pela literatura como o "mito da italianidade" em Caxias do Sul (SANTOS e ZANINI, 2009; HERÉDIA, 2005; CARAGNATO, 2010), e do "espírito obreiro do alemão” em Novo Hamburgo (SCHÜTZ, 1976), numa perspectiva antropológica. Contudo, nosso trabalho está direcionado para o tipo de organização social e para as práticas políticas dos agentes sociais erguidas ao longo da formação destas cidades, voltando-se nosso olhar para os aspectos de participação em grupos e associaçóes, a confiança nas pessoas e nas instituições, o envolvimento cívico, entre outros, assim, numa perspectiva sociológica.

A cidade de Novo Hamburgo, marcada pela colonização alemã, no início do século XIX se constitui em um distrito da cidade de São Leopoldo, sendo emancipada em 5 de abril de 1927. Está localizada a 40 quilômetros da capital do estado, Porto Alegre, integrando a região do Vale do Rio dos Sinos. A cidade é reconhecida como a Capital Nacional do Calçado, com Produto Interno Bruto (PIB) de R 8 8.122.335,91 (mil) e Índice de Desenvolvimento Humano Municipal (IDHM) de 0,747, e com uma população de cerca de 238.940 mil habitantes (IBGE, 2010). 
Já a cidade de Caxias do Sul é marcada pela colonização italiana. Esta teve início nos primeiros anos do século XIX, no lugarejo de Colônia de Caxias, que foi elevada a cidade em $1^{\circ}$ de julho de 1910. Está localizada a 128 quilômetros da capital do estado do Rio Grande do Sul, integrando a região da Serra. A cidade integra, junto a outros municípios, uma região reconhecida pela produção de vinho e derivados, com PIB de R\$ R 20.637.191,76 (mil) e IDHM de 0,782, e tem uma população de 435.564 mil habitantes (IBGE, 2010).

Neste sentido, somados aos aspectos da formação sociocultural e o acúmulo do capital social, para a escolha dos municípios, foram levados em consideração também critérios institucionais, tais como: ambos os municípios são considerados de grande porte $e^{4}$; ambos têm o nível de gestão plena do SUAS ; e ambos dispóem da mesma quantidade de aparelhos públicos, sendo seis CRAS e dois CREAS. Desta forma, coloca-se a problemática: considerando, na sua maioria, as semelhanças institucionais dos municípios, seria o capital social o vetor relacionado com o desempenho institucional das políticas públicas?

Em relação à confiança nas pessoas, numa perspectiva comparada, constata-se em ambos os municípios um baixo percentual de confiança. Contudo, em Caxias do Sul, conforme a Tabela 1, encontra-se maior percentual de entrevistados que dizem que se pode confiar nas pessoas (31\%), em relação a Novo Hamburgo (24\%).

Tabela 1 - Confiança nas pessoas nas cidades de Caxias do Sul e Novo Hamburgo (\%)

\begin{tabular}{l|c|c}
\hline & Caxias do Sul & Novo Hamburgo \\
\hline Entrevistados que confiam nas pessoas & 31 & 24 \\
\hline Entrevistados que não confiam nas pessoas & 69 & 76 \\
\hline Total & 100 & 100 \\
\hline
\end{tabular}

Caxias do Sul n=211 - Novo Hamburgo n=171

Fonte: Elaboração própria.

Guardadas as proporções, em pesquisa realizada por Bastos (2008) comparando o capital social no RS, esse percentual era ainda maior para Caxias do Sul, onde, na opinião de $46 \%$ dos usuários do SUS, podia-se confiar nas pessoas. Neste sentido, pode-se apontar que a sugestão de Giddens (2007) sobre a perda de

\footnotetext{
${ }^{4}$ Entende-se por municípios de grande porte aqueles cuja população é de 101.000 habitantes até 900.000 habitantes (cerca de 25.000 a 250.000 famílias) (BRASIL, 2004).

${ }^{5}$ Gestão total das açóes de assistência social, com foco em organizar a proteção social básica e especial (BRASIL, 2004).
} 
confiança nos países nos últimos anos pode ser experimentada no contexto do Rio Grande do Sul, em especial nas cidades de Caxias do Sul e Novo Hamburgo. Colado a este cenário, a atual crise econômica e política do país contribui para a queda de confiança interpessoal nos governos, respectivamente, nas instituiçóes e nas políticas públicas.

Em relação ao aspecto da confiança nas instituições, a confiança na família é que alcança os escores mais altos e, praticamente, mantém-se idêntica nas duas cidades, sendo 92\% em Caxias do Sul e 91\% em Novo Hamburgo. O aspecto pode ser melhor contemplado na Tabela 2 .

Tabela 2 - Confiança nas instituiçôes nas cidades de Caxias do Sul e Novo Hamburgo (\%)

\begin{tabular}{l|c|c}
\hline & Caxias do Sul & Novo Hamburgo \\
\hline Entrevistados que confiam na família & 92 & 91 \\
\hline Entrevistados que confiam nos vizinhos & 65 & 73 \\
\hline Entrevistados que confiam nas igrejas & 82 & 85 \\
\hline Entrevistados que confiam nas associaçóes de moradores & 70 & 65 \\
\hline Entrevistados que confiam nos sindicatos & 73 & 66 \\
\hline
\end{tabular}

Caxias do Sul n=211 - Novo Hamburgo n=171

Fonte: Elaboração própria.

Como podemos observar, na cidade de Caxias do Sul, os usuários confiam mais nas instituições denominadas "intermediárias", aquelas que não pertencem ao Estado ou à família, no caso, os sindicatos $(73 \%)$ e as associações (70\%). Esse dado aponta para um importante elemento de capital social encontrado em Caxias do Sul, qual seja, a confiança para além das relaçôes de parentesco e daquelas em que o Estado foi sempre o promotor.

Em relação à participação da população em instituições intermediárias, embora este aspecto alcance tímidos escores em ambos os municípios, em Caxias do Sul, observa-se um ambiente mais virtuoso, como segue na Tabela 3. 
Tabela 3 - Participação em instituições e associações nas cidades de Caxias do Sul e Novo Hamburgo (\%)

\begin{tabular}{l|c|c}
\hline & Caxias do Sul & Novo Hamburgo \\
\hline Entrevistados que participam de partidos políticos & 5 & 5 \\
\hline Entrevistados que participam de reunióes políticas & 4 & 7 \\
\hline Entrevistados que participam de comícios & 8 & 13 \\
\hline Entrevistados que participam de associação de moradores & 19 & 14 \\
\hline Entrevistados que participam de associaçóes religiosas & 26 & 25 \\
\hline Entrevistados que participam de associaçóes sindicais & 6 & 5 \\
\hline Entrevistados que participam de ONG & 7 & 7 \\
\hline Entrevistados que participam de Orçamento participativo & 13 & 6 \\
\hline Entrevistados que participam de abaixo assinado & 14 & 7 \\
\hline Entrevistados que participam de manifestaçóes ou protestos & 7 & 3 \\
\hline Entrevistados que participam de greves & 5 & 5 \\
\hline Entrevistados que participam de ocupação de terreno & 6 & 4
\end{tabular}

Caxias do Sul n=211 - Novo Hamburgo n=171

Fonte: Elaboração própria.

Observando-se a Tabela 3, constata-se que, das 13 associaçóes e instituiçóes nas quais os entrevistados disseram participar, em oito delas Caxias do Sul ficou na frente, ao passo que Novo Hamburgo ficou na frente apenas em duas. Chama a atenção que a participação em associações de moradores e orçamento participativo é bem mais expressiva na sociedade caxiense, alcançando índices de 19\% e 13\%, respectivamente, contra $14 \%$ e $6 \%$ em Novo Hamburgo. Constata-se uma igual participação em partidos políticos (5\%) e em ONGs (7\%). Em Novo Hamburgo, tem-se melhores índices apenas em relação à participação em reuniōes políticas e em comícios.

Seguindo a nossa análise, sobre o aspecto do envolvimento cívico, na cidade de Caxias do Sul encontramos um percentual um pouco maior de entrevistados que costumam resolver os problemas do bairro junto com outras pessoas (38\%), que participam de algum grupo no bairro (26\%) e que participaram de algum projeto, mesmo sem nenhum benefício próprio (90\%), conforme a Tabela 4. 
144 | Douglas Marques, Everton Rodrigo Santos e Scarleth Gabriela Ribeiro Duarte

Tabela 4 - Engajamento cívico nas cidades de Caxias do Sul e Novo Hamburgo (\%)

\begin{tabular}{l|c|c}
\hline & Caxias do Sul & Novo Hamburgo \\
\hline $\begin{array}{l}\text { Entrevistados que costumam resolver os } \\
\text { problemas do bairro com outras pessoas }\end{array}$ & 38 & 33 \\
\hline $\begin{array}{l}\text { Entrevistados que participam de algum grupo } \\
\text { ou organização no bairro }\end{array}$ & 26 & 24 \\
\hline $\begin{array}{l}\text { Entrevistados que participariam de um projeto } \\
\text { sem nenhum benefício próprio }\end{array}$ & 90 & 83 \\
\hline
\end{tabular}

Caxias do Sul n=211 - Novo Hamburgo n=171

Fonte: Elaboração própria.

O percentual dos entrevistados que costumam resolver os problemas do bairro junto com outras pessoas é um importante componente de capital social, pois a experiência italiana mostrou-nos que, na região norte, os moradores buscavam atendimento com os representantes distritais (no nosso caso vereadores ou deputados) numa quantidade menor que no Sul e, quando o faziam, eram para resolver problemas coletivos, contribuindo para que aos poucos práticas de clientelismo fossem enfraquecidas (PUTNAM, 2000).

Já em relação ao aspecto de envolvimento em algum grupo ou organização social, Stassen (2011) enfatiza que os mecanismos informais de integração social nas redes societárias que criam as identidades podem ser tão importantes quanto as chamadas políticas sociais de empregos, por exemplo. Sobre a participação voluntária em algum projeto no bairro, segundo Putnam (2000, p. 113), a sua importância se dá, pois, em “[...] regiôes onde a comunidade não costuma participar dos referendos, náo lê jornal, nem participa de associaçóes cívicas, são as mesmas descritas pelos líderes comunitários como política regional clientelista e envolvida por uma cultura de desconfiança”. Neste sentido, em relação ao envolvimento cívico, a cidade de Caxias do Sul parece contar com um estoque maior deste importante elemento do capital social.

Em relação ao Índice de Capital Social (ICS) nas cidades estudadas, consideramos que é possível medir o seu estoque a partir de informaçôes sobre grupos e integrantes de grupos (RIBERO et al., 2012; SANTOS, 2013; INGLEHART, 2001). Os indicadores utilizados para a construção do ICS foram adaptados às condiçóes e características do local analisado ${ }^{6}$. Neste sentido, foram estabelecidas algumas

${ }^{6}$ O Índice de Capital Social (ICS) foi construído de forma idêntica para as duas regióes a partir da seleção de nove questões relativas ao capital social, são elas: (1) "Em termos gerais, o senhor diria que 
afirmaçóes com relação a hábitos e costumes da população, em que, para cada afirmação, foi atribuído valor 2; para cada negaçáo, valor 0; e, para cada possibilidade remota (às vezes, pouco), valor 1 . Desta forma, o índice é formado pela agregação das duas primeiras respostas (indicando as respostas positivas) e pela agregação da última resposta (indicando a resposta negativa).

Desta forma, para verificarmos o acúmulo de capital social, inspirados em Khan e Silva (2002), estabelecemos os seguintes critérios: baixo nível de capital social $-0<\mathrm{ICS} \leq 0,5$; médio nível de capital social - $0,5<$ ICS $\leq 0,8$; alto nível de capital social - $0,8<$ ICS $\leq 1$, conforme a Tabela 5 .

se pode confiar nas pessoas ou não se pode confiar nas pessoas?” Sim (peso 2), Não (peso 0); (2) "Gostaria de saber se o senhor confia muito (peso 2), pouco (peso 1) ou não confia (peso 0) na: igreja, família, vizinhos, associaçóes comunitárias, sindicatos"; (3) "O senhor costuma participar de: partidos políticos, reuniôes políticas, comícios, associações comunitárias, associações religiosas, associaçóes sindicais, conselhos populares, ONGs, orçamento participativo, abaixo assinados, manifestaçóes ou protestos, greves, ocupação de terrenos ou prédios públicos, outros" Sim (peso 2), Não (peso 0); (4) "Nos últimos anos, o senhor tentou resolver algum problema local do bairro/comunidade junto com outras pessoas?" Sim (peso 2), Não (peso 0); (5) "Dentre os grupos que eu vou mencionar, quais deles existem no seu bairro: grupo político, grupo ou associação cultural, grupo educacional, grupo esportivo, grupo de jovens, ONG ou grupo cívico, grupo baseado na comunidade étnica, grupos de mulheres, outro" Sim (peso 2), Não (peso 0); (6) "Atualmente o senhor participa de algum grupo ou organização?" Sim (peso 2), Não (peso 0); (7) "Se precisasse viajar por um ou dois dias, o senhor poderia contar com vizinhos para cuidar da sua casa e/ou filhos?" Sim (peso 2), Provavelmente (peso 1), Não (peso 0); (8) "Em uma situação de emergência como a doença de um familiar ou perda de emprego, o senhor receberia ajuda:” familiares (peso 0), vizinhos (peso 2), colegas de trabalho (peso 2); (9) "Se um projeto da comunidade não lhe beneficia diretamente, mas pode beneficiar outras pessoas do seu bairro, o senhor contribui para este projeto?” Sim (peso 2), Não (peso 0). 
I Douglas Marques, Everton Rodrigo Santos e Scarleth Gabriela Ribeiro Duarte

Tabela 5 - Índice de Capital Social - ICS das cidades de Caxias do Sul e Novo Hamburgo

\begin{tabular}{c|c|c}
\hline & Caxias do Sul & Novo Hamburgo \\
\hline Indicador & Valor & Valor \\
\hline Confiança nas pessoas & 0,313 & 0,246 \\
\hline Confiança nas instituições & 0,380 & 0,388 \\
\hline Participaçáo em grupos e associaçóes & 0,190 & 0,165 \\
\hline Resolver problemas com outras pessoas & 0,379 & 0,327 \\
\hline Conhecimento sobre grupos no bairro & 0,335 & 0,286 \\
\hline Envolvimento em grupo ou organização & 0,261 & 0,240 \\
\hline Confiança nos vizinhos & 0,294 & 0,280 \\
\hline Redes de amizade & 0,250 & 0,250 \\
\hline Engajamento cívico & 0,896 & 0,842 \\
\hline Total & 0,366 & 0,336
\end{tabular}

Caxias do Sul n=211 - Novo Hamburgo n=171

Fonte: Elaboração própria.

De uma maneira geral, podemos constatar que o município de Caxias do Sul obteve escores um pouco melhores do que o município de Novo Hamburgo, sendo os mais expressivos os indicadores de "confiança interpessoal" $(0,313)$ e o "conhecimento sobre grupos no bairro" (0,335). Para o contexto de Novo Hamburgo, apenas o indicador "confiança nas instituições" $(0,338)$ apresentou um escore um pouco superior em relação à Caxias do Sul. O indicador "redes de amizade" ficou idêntico nos dois municípios $(0,250)$.

Constata-se que o indicador "engajamento cívico" foi o mais importante (de maior peso) na determinação do ICS em ambas as cidades. De forma particular, na região de Novo Hamburgo, a participação em grupos e associaçóes, pela população, mostra-se bastante inexpressiva $(0,165)$. Neste sentido, Caxias do Sul apresentou índice um pouco maior de capital social $(0,366)$ em relação à região de Novo Hamburgo $(0,336)$. De uma maneira geral, os valores encontrados apontam para um baixo nível de capital social nas duas regióes, sendo o de Novo Hamburgo o menor.

\section{Capital social e desempenho institucional no SUAS de Caxias do Sul e Novo Hamburgo}

Busca-se identificar, então, em que medida há uma regularidade das ações do SUAS dos municípios de Caxias do Sul e Novo Hamburgo. Com esse objetivo, perguntou-se à população do SUAS, quando esta procurou os aparelhos públicos CRAS/CREAS, em que medida seus problemas haviam sido resolvidos. A fim de analisarmos a questão, segue a Tabela 6 . 
Tabela 6 - Regularidade com que as instituiçôes do SUAS resolvem os problemas nas cidades de Caxias do Sul e Novo Hamburgo (\%)

\begin{tabular}{l|c|c}
\hline & Caxias do Sul & Novo Hamburgo \\
\hline Sempre & 56 & 53 \\
\hline Às vezes & 23 & 26 \\
\hline Nunca & 5 & 8 \\
\hline Náo sabem & 16 & 13 \\
\hline Total & 100 & 100 \\
\hline
\end{tabular}

Caxias do Sul n=211 - Novo Hamburgo n=171

Fonte: Elaboração própria.

Sobre o aspecto da regularidade das açóes, $56 \%$ dos usuários do SUAS de Caxias do Sul avaliam que, quando procuram os aparelhos públicos - CRAS e CREAS - têm seu problema sempre resolvido. Para os usuários do SUAS de Novo Hamburgo, esse percentual cai um pouco, ficando em 53\%. No outro extremo, o percentual de usuários que avaliam que o problema nunca é resolvido é de 5\%, no SUAS de Caxias do Sul; já para o SUAS Novo Hamburgo, esse percentual é um pouco mais elevado, ficando em $8 \%$.

Quanto ao aspecto da capacidade das instituiçóes em identificar os problemas locais, na avaliação dos usuários, em Novo Hamburgo, as instituições do SUAS conseguem identificar melhor as demandas da população, com $51 \%$ dos entrevistados afirmando que os aparelhos públicos - CRAS e CREAS - conhecem os problemas do bairro. Em Caxias do Sul, o percentual cai para 40\%. O aspecto pode ser explorado por meio da Tabela 7.

Tabela 7 - Em que medida as instituições do SUAS conhecem os problemas locais nas cidades de Caxias do Sul e Novo Hamburgo (\%)

\begin{tabular}{l|c|c}
\hline & Caxias do Sul & Novo Hamburgo \\
\hline Conhecem os problemas & 40 & 51 \\
\hline Conhecem pouco os problemas & 34 & 33 \\
\hline Não conhecem & 10 & 8 \\
\hline Não sabem & 16 & 8 \\
\hline Total & 100 & 100 \\
\hline
\end{tabular}

Caxias do Sul N=211 - Novo Hamburgo N=171

Fonte: Elaboração própria.

A importância deste aspecto vai ao encontro do que Putnam (2000, p. 25) já afirmava, pois, “[...] uma instituição democrática tem que ser ao mesmo tempo 
sensível e eficaz: sensível às demandas do eleitorado e eficaz na utilização de recursos limitados para atender essas demandas".

Sobre o aspecto da eficácia ligado à capacidade das instituições de cumprirem seus objetivos, Putnam (2000, p. 25) salienta a sua vital importância, pois “[...] a qualidade do governo interessa à vida das pessoas: concedem-se bolsas de estudo, pavimentam-se estradas, vacinam-se crianças, ou então, se o governo falhar, nada disso acontece". Neste sentido, buscou-se identificar em que medida as instituiçóes do SUAS atingem seus objetivos, conforme Tabela 8.

Tabela 8 - Em que medida as instituições do SUAS atingem seus objetivos nas cidades de Caxias do Sul e Novo Hamburgo (\%)

\begin{tabular}{l|c|c}
\hline & Caxias do Sul & Novo Hamburgo \\
\hline Atingem os propósitos & 69 & 64 \\
\hline Atingem em parte os propósitos & 14 & 22 \\
\hline Não atingem os propósitos & 4 & 5 \\
\hline Não sabem & 13 & 9 \\
\hline Total & 100 & 100 \\
\hline
\end{tabular}

Caxias do Sul n=211 - Novo Hamburgo n=171

Fonte: Elaboração própria.

Dessa forma, em Caxias do Sul, constata-se que, para 69\% da população, as instituiçôes do SUAS atingem seus objetivos. Para o SUAS de Novo Hamburgo, esse percentual cai um pouco, ficando em $64 \%$.

Por fim, sobre o tema do desempenho institucional, buscamos avaliar a satisfação da população com as instituições do SUAS ${ }^{7}$. Neste sentido, buscamos verificar se há uma aproximação entre o estoque de capital social e a avaliação positiva das instituiçôes, conforme apontava Putnam (2000) nos seus estudos. Iniciamos a análise pela Tabela 9, que segue.

\footnotetext{
7 Da mesma forma que Santos (2013), compartilhamos da compreensão de Popkin (1994) sobre a "racionalidade de baixa informação". Para o autor, o cidadão comum pode sim adquirir conhecimento sobre seu entorno, sobre políticas econômicas ou de saúde, mesmo com baixa informação, pois são eles, os cidadáos, que vivem o cotidiano das cidades, que compram, que vão ao médico, que têm filhos na escola e, portanto, que podem emitir uma opinião com base na sua experiência. Assim, a satisfação ou não com uma política pública da população não é uma mera opinião, mas sim um indicador do funcionamento desta política.
} 
Tabela 9 - Satisfação institucional com o SUAS nas cidades de Caxias do Sul e Novo Hamburgo (\%)

\begin{tabular}{l|c|c}
\hline & Caxias do Sul & Novo Hamburgo \\
\hline Muito satisfeito & 31 & 28 \\
\hline Satisfeito & 41 & 48 \\
\hline Nem satisfeito, nem insatisfeito & 5 & 4 \\
\hline Pouco satisfeito & 10 & 13 \\
\hline Insatisfeito & 0,5 & 3 \\
\hline Náo sabem & 13 & 4 \\
\hline Total & 100 & 100 \\
\hline
\end{tabular}

Caxias do Sul n=211 - Novo Hamburgo n=171

Fonte: Elaboração própria.

Podemos constatar que, em Caxias do Sul, $31 \%$ da população do SUAS está muito satisfeita com as suas instituições. Já em Novo Hamburgo, esse percentual cai um pouco, indicando $28 \%$. Por outro lado, o percentual da população insatisfeita com as instituições em Caxias do Sul é de 0,5\%; já em Novo Hamburgo o percentual sobe para $3 \%$.

Desta forma, podemos considerar que as instituiçóes do SUAS de Caxias do Sul contam com um melhor desempenho institucional quando comparadas com a realidade de Novo Hamburgo. Assim, em Caxias do Sul, a população do SUAS avalia um pouco melhor os aspectos de regularidade e de realização dos objetivos das instituições. Para a realidade de Novo Hamburgo, a população avalia um pouco melhor a capacidade das instituiçôes de identificar as demandas da população. Assim, pode-se sugerir as razões da satisfação institucional estarem um pouco melhor avaliadas na realidade do SUAS de Caxias do Sul. Contudo, uma questáo permanece: existe associação entre o capital social e desempenho institucional nas cidades em tela?

Conforme referido anteriormente, o capital social existente em uma sociedade pode ser um elemento de sustentação teórica para o desafio da participação no âmbito das políticas públicas. Assim, na sequência, buscaremos analisar em que medida o acúmulo de capital social existente nos municípios de Caxias do Sul e Novo Hamburgo está associado com a qualidade da participação nas respectivas cidades. Para tal, utilizaremo-nos do Teste Qui-quadrado $\left(\mathrm{X}^{2}\right)$, que permite testar a significância (grau de associação) entre duas variáveis qualitativas (MEIRELLES, 2014). Desta forma, quando o valor do teste ficar entre $0 \%$ (Sig $=0,00)$ e $0,5 \%$ (Sig $=0,05)$, devemos aceitar a hipótese alternativa, qual seja, capital social está associado com o desempenho institucional no SUAS, e rejeitar a hipótese nula, qual seja, capital social não está associado com o desempenho institucional no SUAS, 
150 I Douglas Marques, Everton Rodrigo Santos e Scarleth Gabriela Ribeiro Duarte indicando que as variáveis capital social e desempenho institucional no SUAS estão associadas estatisticamente.

Tabela 10 - Correlação entre capital social e níveis de desempenho institucional do SUAS nas cidades de Caxias do Sul e Novo Hamburgo

\begin{tabular}{|c|c|c|c|c|c|}
\hline $\begin{array}{r}\text { Níveis de desempenho } \\
\text { institucional }\end{array}$ & 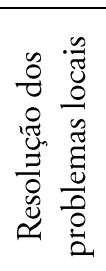 & 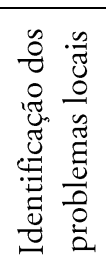 & 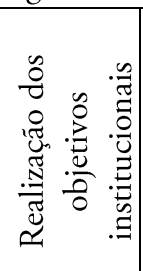 & 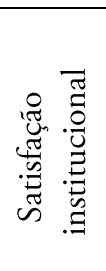 & \\
\hline Confiança nas pessoas & $\begin{array}{l}0,363 \\
0,107\end{array}$ & $\begin{array}{l}0509 \\
0457\end{array}$ & $\begin{array}{l}0,122 \\
0,065\end{array}$ & $\begin{array}{l}0,700 \\
0,012\end{array}$ & $\begin{array}{l}\text { Caxias do Sul } \\
\text { Novo Hamburgo }\end{array}$ \\
\hline Confiança nas igrejas & $\begin{array}{l}0,230 \\
0,421\end{array}$ & $\begin{array}{l}0,278 \\
0,183 \\
\end{array}$ & $\begin{array}{l}0,179 \\
\mathbf{0 , 0 3 6}\end{array}$ & $\begin{array}{l}0,033 \\
0,018 \\
\end{array}$ & $\begin{array}{l}\text { Caxias do Sul } \\
\text { Novo Hamburgo } \\
\end{array}$ \\
\hline Confiança nos sindicatos & $\begin{array}{l}0,082 \\
0,035\end{array}$ & $\begin{array}{l}0,641 \\
0,008\end{array}$ & $\begin{array}{l}0,116 \\
0,059\end{array}$ & $\begin{array}{l}0,138 \\
0,016\end{array}$ & $\begin{array}{l}\text { Caxias do Sul } \\
\text { Novo Hamburgo }\end{array}$ \\
\hline Participação em abaixo assinado & $\begin{array}{l}0,035 \\
0,797\end{array}$ & $\begin{array}{l}0,082 \\
0,172\end{array}$ & $\begin{array}{l}0,338 \\
0,877\end{array}$ & $\begin{array}{l}\mathbf{0 , 0 4 2} \\
0,358\end{array}$ & $\begin{array}{l}\text { Caxias do Sul } \\
\text { Novo Hamburgo }\end{array}$ \\
\hline Engajamento em grupos e org. sociais & $\begin{array}{l}0,403 \\
0,425\end{array}$ & $\begin{array}{l}\mathbf{0 , 0 1 1} \\
0,774\end{array}$ & $\begin{array}{l}0,194 \\
0,642\end{array}$ & $\begin{array}{l}0,117 \\
0,624\end{array}$ & $\begin{array}{l}\text { Caxias do Sul } \\
\text { Novo Hamburgo }\end{array}$ \\
\hline Participação em partidos políticos & $\begin{array}{l}0,868 \\
0,682\end{array}$ & $\begin{array}{l}0,841 \\
0,935\end{array}$ & $\begin{array}{l}0,957 \\
0,511\end{array}$ & $\begin{array}{l}0,888 \\
0,050\end{array}$ & $\begin{array}{l}\text { Caxias do Sul } \\
\text { Novo Hamburgo }\end{array}$ \\
\hline Participação em comícios & $\begin{array}{l}0,241 \\
0,180\end{array}$ & $\begin{array}{l}0,378 \\
0,211\end{array}$ & $\begin{array}{l}0,236 \\
0,690\end{array}$ & $\begin{array}{l}\mathbf{0 , 0 3 9} \\
0,947\end{array}$ & $\begin{array}{l}\text { Caxias do Sul } \\
\text { Novo Hamburgo }\end{array}$ \\
\hline Participação em ONG & $\begin{array}{l}0,166 \\
0,905 \\
\end{array}$ & $\begin{array}{l}0,172 \\
0,730 \\
\end{array}$ & $\begin{array}{l}0,433 \\
0,548 \\
\end{array}$ & $\begin{array}{l}0,203 \\
0,042 \\
\end{array}$ & $\begin{array}{l}\text { Caxias do Sul } \\
\text { Novo Hamburgo }\end{array}$ \\
\hline Participação em orçamento participativo & $\begin{array}{l}0,703 \\
0,729 \\
\end{array}$ & $\begin{array}{l}0,241 \\
0,102 \\
\end{array}$ & $\begin{array}{l}0,724 \\
0,626 \\
\end{array}$ & $\begin{array}{l}0,747 \\
\mathbf{0 , 0 4 0}\end{array}$ & $\begin{array}{l}\text { Caxias do Sul } \\
\text { Novo Hamburgo }\end{array}$ \\
\hline $\begin{array}{l}\text { Participação em manifestações ou } \\
\text { protestos }\end{array}$ & $\begin{array}{l}0,644 \\
0,967 \\
\end{array}$ & $\begin{array}{l}0,137 \\
0,943 \\
\end{array}$ & $\begin{array}{l}0,456 \\
0,812\end{array}$ & $\begin{array}{l}\mathbf{0 , 0 5 0} \\
0,276 \\
\end{array}$ & $\begin{array}{l}\text { Caxias do Sul } \\
\text { Novo Hamburgo }\end{array}$ \\
\hline Participação em ocupação de terreno & $\begin{array}{l}0,177 \\
0,935 \\
\end{array}$ & $\begin{array}{l}0,594 \\
0,675 \\
\end{array}$ & $\begin{array}{l}0,391 \\
0,611\end{array}$ & $\begin{array}{l}0,030 \\
0,944 \\
\end{array}$ & $\begin{array}{l}\text { Caxias do Sul } \\
\text { Novo Hamburgo }\end{array}$ \\
\hline Participação em outros espaços & $\begin{array}{l}0,865 \\
0,531\end{array}$ & $\begin{array}{l}0,930 \\
0,308\end{array}$ & $\begin{array}{l}0,897 \\
0,813\end{array}$ & $\begin{array}{l}\mathbf{0 , 0 0 1} \\
0,173\end{array}$ & $\begin{array}{l}\text { Caxias do Sul } \\
\text { Novo Hamburgo }\end{array}$ \\
\hline
\end{tabular}

Caxias do Sul n=211 - Novo Hamburgo n=171

Fonte: Elaboração própria.

\footnotetext{
${ }^{8}$ No município de Caxias do Sul o orçamento participativo é denominado de orçamento comunitário pela gestão pública.
} 
Constata-se, numa análise comparada entre as cidades, um volume igual de associações entre capital social e desempenho institucional; contudo, sugere-se diferenças entras as cidades. Para o contexto de Novo Hamburgo, o contexto de confiança nas pessoas e confiança nos sindicatos está relacionado com a capacidade das instituições de identificação dos problemas locais e de atingirem seus propósitos. $\mathrm{Na}$ cidade de Caxias do Sul, a análise dos dados permite-nos sugerir o capital social como um importante vetor para o desempenho institucional nas políticas públicas, pois a participação de abaixo-assinados e em grupos e associações guarda relação direta com a capacidade de identificaçáo dos problemas locais e com a frequência na regularidade das açôes institucionais. Sobre esta última variável, atrelado ao processo de formação sociocultural da cidade de Caxias do Sul, por meio de pesquisa documental realizada, registra-se a existência de 22 associações e clubes, contra seis em Novo Hamburgo; somado a isto, a cidade de Caxias do Sul conta com 182 associaçôes de moradores, contra 12 da cidade de Novo Hamburgo. Desta forma, estatisticamente podemos aceitar nossa hipótese alternativa, qual seja, que existe relação positiva entre capital social e desempenho institucional no SUAS. Numa perspectiva comparada, em Caxias do Sul e Novo Hamburgo constatamos um volume de 16 associaçóes significativas $(\leq 0,05)$, havendo uma igualdade de $8 \mathrm{em}$ cada cidade.

Uma vez demonstrada a associação entre capital social e o desempenho institucional, pretendemos, por meio do teste de regressão logística multinominal, aferir o poder explicativo das variáveis e, assim, descobrirmos quais delas estão impactando no desempenho institucional. Desta forma, tomamos como elementos do desempenho institucional a regularidade das ações, a identificação das demandas da população e a realização dos objetivos institucionais e, assim, cruzamos com a confiança nas pessoas, confiança nas instituiçóes, participação em grupos e associaçóes, envolvimento cívico e resolução de problemas com outras pessoas, elementos do capital social.

Em relação ao SUAS de Novo Hamburgo, a confianças nas pessoas $(\mathrm{N}=9,332, \mathrm{P}=0,053)$, a participação em $\mathrm{ONG}^{9}(\mathrm{~N}=18,157, \mathrm{P}=0,021)$ e em greves $(\mathrm{N}=19,265, \mathrm{P}=0,014)$ foram as variáveis independentes, com significância estatística que explica o seu desempenho institucional. Já em relação ao SUAS de Caxias do Sul,

9 São denominadas de Organizaçôes da Sociedade Civil (OSC), novo Marco Regulatório das Organizaçóes da Sociedade Civil, Lei no 13.019/2014. 
encontramos um número maior de variáveis explicativas. Assim, a confiança na igreja ( $\pi=17,171, \mathrm{P}=0,009)$, nos vizinhos $(\pi=18,879, \mathrm{P}=0,016)$, a participação em partidos políticos $(\pi=15,176, \mathrm{P}=0,056)$, em associaçóes sindicais $(\pi=15,647$, $\mathrm{P}=0,048)$, em abaixo-assinados $(\pi=21,021, \mathrm{P}=0,010)$, a capacidade de resolver problemas com outras pessoas $(\pi=9,878 ; \mathrm{P}=0,043)$ e o engajamento cívico ( $\pi$ $=18,659 ; \mathrm{P}=0,017)$ foram as variáveis independentes, com significância estatística que explica o seu desempenho institucional.

\section{Considerações finais}

Além do importante papel das instituições, dos desafios orçamentários dos governos, o capital social é também uma variável extremamente relevante na análise do desempenho institucional das políticas públicas. Essa relevância ocorre já que o capital social capta fatores mais intangíveis, contudo, fundamentais, que não podem ser negligenciados nas novas discussóes sobre as políticas, em especial no seu aspecto de participação. À luz da teoria do capital social, é possível olhar a realidade, identificando que os recursos sociais, entre eles a confiança interpessoal, o envolvimento cívico e a participação, estão presentes nas instituições e nas sociedades que se constituíram eficazes e democráticas.

Em relação à satisfação institucional, em ambos os municípios, nossa pesquisa também apontou sua relação com os elementos do capital social, assim, na medida em que cresce o estoque de capital social, melhor a população avalia as políticas públicas, em especial, o SUAS. Nesse sentido, nosso artigo levou-nos a compreender que o acúmulo de capital social, sendo os mais expressivos a confiança e a participação em grupos e organizações, tem relação positiva com o desempenho institucional do SUAS no contexto dos municípios de Caxias do Sul e Novo Hamburgo.

Douglas Marques é Doutor e mestre em Diversidade Cultural e Inclusão Social, pela Universidade Feevale. Pós-doutorando em Diversidade Cultural e Inclusão Social e membro do grupo de pesquisa Metropolização e Desenvolvimento Regional pela Universidade Feevale. Professor na Universidade Estadual de Maringá (UEM). E-mail: douglas.sersocial@gmail.com.

- Everton Rodrigo Santos é Pós-Doutor e Doutor em Ciência Politica pela Universidade Federal do Rio Grande do Sul-UFRGS. Professor no Programa de Pós-Graduação em Diversidade Cultural 


\section{e Inclusão Social e Integrante do grupo de pesquisa Metropolização e Desenvolvimento Regional pela Universidade Feevale. E-mail: chabert89@gmail.com.}

- Scarleth Gabriela Ribeiro Duarte é Graduanda em Publicidade e Propaganda e Bolsista de Iniciação Científica do Grupo de pesquisa Metropolização e Desenvolvimento Regional pela Universidade Feevale. Email: scarleth.duarte@live.ie.

\section{Referências}

ARROW, Keneth J. The limits of Organization. London: Norton \& Company, 1974.

BANDERA, P. Algumas hipóteses sobre as causas das diferenças regionais quanto ao capital social no Rio Grande do Sul. In.: CORREA, S (org.). Capital social e desenvolvimento regional. Santa Cruz do Sul: EDNISC. 2003.

BAQUERO, C. M. J.; CASTRO, H. C. O.; RANINCHESKI, S. . (Des)confiança nas instituições e partidos políticos na constituição de uma democracia inercial no Brasil: o caso das eleiçôes de 2014. Política \& Sociedade (Impresso), v. 15, p. 9-38, 2016.

BAQUERO, Marcello. Qual Democracia para a América Latina: capital social e empoderamento são a resposta? Porto Alegre: Ed. UFRGS, 2013.

BAQUERO, Marcello; PRÁ, Jussara. A democracia brasileira e a cultura política no Rio Grande do Sul. Porto Alegre: Ed. UFRGS, 2007.

BARBETTA, Pedro. Estatística aplicada às ciências sociais. Florianópolis: Edusfc, 2010.

BASTOS, Francisco A. A inserção da odontologia em quatro municípios em gestão plena do Sistema Municipal do SUS no Rio Grande do Sul: um estudo de avaliação institucional. 2008. 328 f. Tese (Doutorado em Odontologia) - Programa de Pós-Graduação em Odontologia, Universidade Luterana do Brasil, Canoas, 2008.

BOURDIEU, Pierre. Le capital social. Actes de la recherche en sciences socieales, v. 31, p. 2-3, 1980.

BOZEMAN, Barry; PANDEY, Sanjay K. Public management decision making: effects of decision contet. Public Adminitration Review. v. 64, n. 5, p. 553-565, 2004.

BRASIL. Ministério do Desenvolvimento Social e Combate a Fome. Secretaria Nacional de Assistência Social. Norma Operacional Básica (NOB SUAS). Brasília, 2015.

BRAZIL. The economist, 2019. Disponível em: <http://country.eiu.com/brazil>. Acesso em: 12 set. 2019.

CARAGNATO, L. (2010). Presença e contribuição dos afro-descendentes no município de Caxias do Sul - 1875 a 1950. MÉTIS: história \& cultura - v. 9, n. 17, p. 201-215, jan./jun. 
COLEMAN, James S. Social Capital in the Creation of Human Capital. American Journal of Sociology, v. 94, suppl. Organizations and Institucions: Sociological and Economic Approaches to the Analysis of Social Structure, p. S95-S120, 1988.

DOWBOR, Ladislaw. A reprodução Social: descentralização e participação - as novas tendências. Rio de Janeiro: Vozes, 2003. v. III.

FERRAZ, Francisco. Brasil: a cultura política de uma democracia mal resolvida. Porto Alegre: Ad2000, 2016.

A Infraestrutura social da democracia americana. Porto Alegre: PUCRS, 1971.

FUKUYAMA, Francis. Confiança: as virtudes sociais e a criaçáo da prosperidade. Rio de Janeiro: Rocco, 1996.

GIDDENS, Anthony (Org.). O debate global sobre a terceira via. São Paulo: UNESP, 2007.

GUSTAFSSON, Gunnel. Symbolic and pseudo policies as responses to diffusion of Power. Policy sciences, v. 5, n. 3, p. 269-287, 1983.

HANIFAN, Lyda J. The rural school community center. In: American Academy of Political and Social Science. Annals of the American Academy of Political and Social Science. New Possibilities in Education. 1916. v. 67, p. 130-138.

HERÉDIA, V. B. M. (2005). O mito do imigrante no imaginário da cultura. MÉTIS: história \& cultura-v. 4, n. 8, p. 233-244, jul./dez.

INGLEHART, Ronald. Modernización y posmodernización: el cambio cultural, económico y político en 43 sociedades. Madrid: Centro de Investigaciones Sociológicas/Siglo Veintiuno, 2001.

INSTITUTO BRASILEIRO DE GEOGRAFIA E ESTATÍSCA (IBGE). Caracterização dos municípios do Estado do Rio Grande do Sul. 2010. Disponível em: https://cidades.ibge.gov.br/brasil/rs/panorama. Acesso em: 20 mar. 2012.

KHAN, A. S.; SILVA, L. M. R. (2012). Avaliação do Projeto São José no Estado do Ceará: Estudo de Caso. UFC /CCA /DEA, Fortaleza, Ceará.

LAHERA, Eugenio. Introducción a las políticas públicas. Chile: Fondo de Cultura Económica, 2012.

LOWI, Theodore J. American Business, public policy, case studies, and political theory. World Politics, v. 16, n. 4, p. 667-715, 1964.

MEIRELLES, Mauro. O uso do SPSS (Statistical Package for the Social Sciences) na Ciência Política: uma breve introdução. Revista Pensamento Plural, n. 15, p. 65-91, jan./jun. 2014.

MICELI, Sergio (Org.). O que ler na ciência social brasileira (1970-1995). São Paulo: Sumaré, 1999.

NORTH, Douglass. Institutions, institutional change and economic performance. Cambridge: Cambridge University Press, 2007.

OLSON, Mancur. A lógica da ação coletiva: os benefícios públicos e uma teoria dos grupos sociais. São Paulo: EDUSP, 1999.

PASE, Hemerson. L. Capital social e desenvolvimento: a experiência do Rio Grande do Sul. Pelotas: Ed.UFPEL, 2016.

PASE, Hemerson L.; SANTOS, Everton R. Capital social e políticas públicas na América Latina. In: BAQUERO, Marcello (Org.). Cultura(s) política(s) e democracia no século XXI na América Latina. Porto Alegre: UFRGS, 2011. v. 1, p. 69-93.

PUTNAM, Robert. Comunidade e democracia: a experiência da Itália moderna. São Paulo: FGV, 2000 . 
RIBEIRO, I; FERNANDES, E; RIBEIRO, H. A importância do capital social para o desenvolvimento de uma regiáo. Revista RURIS, v. 6, no 1, mar., 2012.

SANTOS, Everton. Democracia e desenvolvimento: desafios da sociedade gaúcha. Ijuí: Edjuí, 2013.

SANTOS Everton; NUNES, Margarete Fagundes. Capital Social e políticas públicas: um estudo comparado no Vale do Rio dos Sinos. Revista de Administração Pública, v. 50, n. 1, p. 129-149, jan./fev. 2016.

SANTOS, M. de O; ZANINI, M. C. C. Especificidades da Identidade de descendentes de italianos no sul do Brasil: breve análise das regióes de Caxias do Sul e Santa Maria. Revista Antropolítica, Niterói, n. 27, p. 21-41, 2. Sem., 2009.

SCHÜTZ, M.M.E. Novo Hamburgo: sua história, sua gente. Porto Alegre: Pollott., 1976.

SZRETER S. Social Capital: critical perspectives. EUA: OXFORD University Press., 1999.

SECCHI, L. Políticas Públicas: conceitos, esquemas de análise, casos práticos. São Paulo: Cengage Learning, 2014.

SOUZA, Celina. Políticas públicas: uma revisão da literatura. Revista Sociologias, n. 16, p. 20-45, 2006.

STASSEN, Jean-François. Exclusion and participation: can the excluded become able to participate? Belgium: Université de Liége, 1999.

SZRETER S. Social Capital: critical perspectives. Oxford: Oxford University Press, 1999.

TABELLINI, G. Culture and institutions: economic development in the regions of Europe. Estados Unidos da América: CESIFO, 2005.

WITTMANN, Milton L.; RAMOS, Marília P. (Org.). Desenvolvimento regional: Capital social, redes e planejamento. Santa Cruz do Sul: EDUNISC, 2004.

WILSON, James Q. American goverment: institutions and policies. Lexington: Heart \& Co., 1983.

Texto recebido em 14 de abril de 2018. Aprovado em 19 de novembro de 2019. 